\title{
Fluorescence Probe and Scanning Force Microscopic Studies of Water Soluble Comb-Shaped Copolymers Consisting of a Hydrophobic Poly( $p$-alkylstyrene) Main Chain and Hydrophilic Poly(ethylene oxide) Grafted Chains
}

\author{
Seigou Kawaguchi, $,^{\dagger}, \dagger^{\dagger}$ Mohd. ManiruZZaman, Kouji Katsuragi, Haruki Matsumoto, IRIAny, \\ Koichi ITo ${ }^{\dagger}$ Norbert HugenberG, ${ }^{*}$ and Manfred SCHMIDT* \\ Department of Materials Science, Toyohashi University of Technology, Tempaku-cho, \\ Toyohashi 441-8580, Japan \\ *Institute of Physical Chemistry, University of Mainz, 11 Welderweg, Mainz 55099, Germany
}

(Received September 19, 2001; Accepted February 28, 2002)

\begin{abstract}
Solution properties of regular amphiphilic comb-shaped polymers have been studied in water by means of fluorescence technique using pyrene as a probe, dynamic light scattering, ${ }^{1} \mathrm{H}$ NMR, and scanning force microscopy (SFM). They consist of a hydrophobic poly( $p$-alkylstyrene) as a main chain and hydrophilic poly(ethylene oxide) (PEO) chains as a graft chain. Two types of the comb-shaped polymers have been explored, which were prepared by micellar, organized homopolymerization of amphiphilic PEO macromonomers $(\mathbf{1})\left(\mathrm{C}_{1}-\mathrm{EO}_{n}-\left(\mathrm{CH}_{2}\right)_{m}-\mathrm{S}\right.$, with a $p$-alkylstyrene $\left(\left(\mathrm{CH}_{2}\right)_{m}\right.$-S) end group, with $m=1$ and 7 , and a PEO chain with $n=18,46,115$, and 469) and by copolymerization of $\mathrm{C}_{1}$ $\mathrm{EO}_{18}-\left(\mathrm{CH}_{2}\right)_{7}-\mathrm{S}$ with styrene in water, respectively. Partitioning, $I_{1} / I_{3}$, and excimer formation of pyrene were studied for their dilute aqueous solutions, and rationalized with the local concentration and structure of the comb-shaped polymers. Hydrophobic pyrene molecules were principally dissolved into the vicinity of the hydrophobic $p$-heptylstyrene main chain of the comb-shaped polymers. The nature of the hydrophobic main chain of poly(styrene- $\left.\mathrm{co}-\mathrm{C}_{1}-\mathrm{EO}_{18}-\left(\mathrm{CH}_{2}\right)_{7}-\mathrm{S}\right)$ was found to be essentially similar to that of a series of poly $\left(\mathrm{C}_{1}-\mathrm{EO}_{n}-\left(\mathrm{CH}_{2}\right)_{m}-\mathrm{S}\right)$. Direct observation of single macromolecule of poly $\left(\mathrm{C}_{1}-\mathrm{EO}_{46}-\left(\mathrm{CH}_{2}\right)_{7}-\mathrm{S}\right)$ by SFM revealed a high molecular weight, cylindrical brush-like conformation with $c a .12 .8 \mathrm{~nm}$ in thickness. In contrast, small fine particles were observed for poly(styrene-co- $\left.\mathrm{C}_{1}-\mathrm{EO}_{18}-\left(\mathrm{CH}_{2}\right)_{7}-\mathrm{S}\right)$, suggesting the formation of a unimolecular micelle in water.

KEY WORDS Poly(ethylene oxide) Macromonomer / Amphiphilic Graft Copolymer / Combshaped Polymer / Scanning Force Microscopy / Branched Polymer / Pyrene / Fluorescence Spectroscopy / Unimolecular Micelle / Polymacromonomer /
\end{abstract}

Micellization of amphiphilic polymers in a selective solvent has been of continuing interest over the past two decades. This is not only because of their biological relevance but also because of their usefulness for such industrial applications as paints, coatings, cosmetics, inks, and oil recovery. ${ }^{1-5}$ Aggregation behavior of diblock copolymers in the selective solvent has extensively been studied from the experimental and theoretical viewpoints. In contrast, a very limited studies on the association of the multi-block copolymers as well as graft copolymers have been reported. ${ }^{6-11}$ A reason is due to the difficulty in the preparation of well-defined graft copolymers. Macromonomer method is one of the promising ones for their preparation, at least in the sense that the grafted chain is pre-characterized. ${ }^{12,13}$ The conventional radical copolymerizations of low molecular weight monomer with macromonomer, however, have been pointed out to afford the graft copolymers with significant heterogeneities in the molecu- lar weight and the composition. ${ }^{14}$ These would make the relevant characterization techniques inefficient and their association behavior indefinitive.

The graft copolymers are expected to form much variety of organized structures depending on the composition, sequence, and length of the grafted chain as well as solvent quality. One of the unique properties of the graft copolymers in a selective solvent would be that they allow to form a unimolecular micelle with intramolecular association. ${ }^{15-20}$ Recently, Kikuchi et al. ${ }^{21}$ have rationalized the association diagram of a well-defined poly(methyl methacrylate)graft-poly(styrene) as a function of excluded-volume parameter, $v=1 / 2-\chi$, where $\chi$ is the monomermonomer interaction parameter. From light scattering experiments, they clearly demonstrated that the graft copolymers form micelles with unimolecularly organized structures in a selective solvent for the grafted chain but in the solvent for backbone they form flower-

\footnotetext{
To whom correspondence should be addressed (Tel: +81-532-44-6814, Fax: +81-532-48-5833, E-mail: itoh@tutms.tut.ac.jp).

${ }^{\dagger}$ Present address: Department of Polymer Science and Engineering, Faculty of Engineering, Yamagata University, Jonan, Yonezawa $992-$ 8510 , Japan.
} 

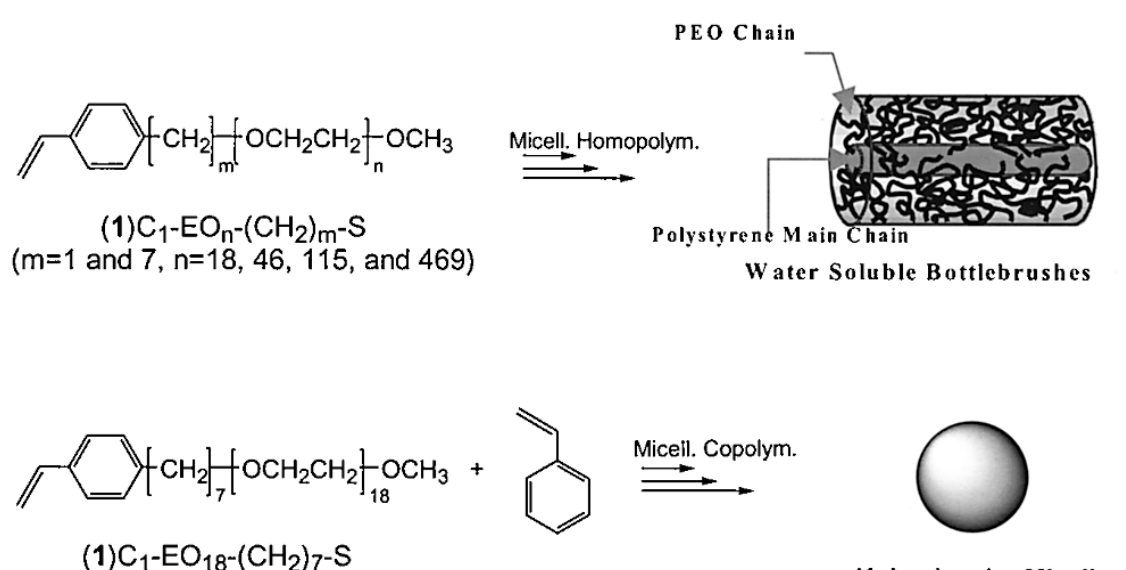

Unimolecular Micelle

Scheme 1.

like micelle and/or flower-connecting micelle. ${ }^{21}$

In the previous papers, ${ }^{22-24}$ we reported that micellar, organized homopolymerization of amphiphilic $\omega$ methoxy- $\alpha$ - $p$-styrylalkyl-poly(ethylene oxide) (PEO) macromonomers (1) $\left(\mathrm{C}_{1}-\mathrm{EO}_{n}-\left(\mathrm{CH}_{2}\right)_{m}-\mathrm{S}\right)$ unusually rapidly proceeds to quantitatively afford regular combshaped polymers with high degree of polymerization. Quite recently, we have also reported that micellar copolymerization of $\mathrm{C}_{1}-\mathrm{EO}_{18}-\left(\mathrm{CH}_{2}\right)_{7}-\mathrm{S}$ with a limited amount of styrene solubilized therein proceeds in the manner of a pseudo-living radical copolymerization with highly limited terminations between compartmentalized (isolated) propagating radicals. ${ }^{25,26}$ At an equimolar styrene with $\mathrm{C}_{1}-\mathrm{EO}_{18}-\left(\mathrm{CH}_{2}\right)_{7}-\mathrm{S}$ the copolymerization proceeded apparently transparently and azeotropically to quantitatively afford a water soluble, highly branched and graft copolymer of poly(styreneco- $\left.\mathrm{C}_{1}-\mathrm{EO}_{18}-\left(\mathrm{CH}_{2}\right)_{7}-\mathrm{S}\right)$ with high degree of polymerization. The copolymerization, therefore, would be expected to result in the graft copolymers with relatively narrower heterogeneity in the composition and molecular weight than those prepared in the conventional homogeneous copolymerization.

The present study is focused on aqueous solution behavior of the resulting amphiphilic combshaped copolymer, poly (styrene-co- $\mathrm{C}_{1}-\mathrm{EO}_{18}-\left(\mathrm{CH}_{2}\right)_{7}-$ $\mathrm{S})$ and homopolymers, poly $\left(\mathrm{C}_{1}-\mathrm{EO}_{n}-\left(\mathrm{CH}_{2}\right)_{m}-\mathrm{S}\right)$. They consist of a hydrophobic poly ( $p$-alkylstyrene) as a main chain and hydrophilic PEO chains surrounding it (see, Scheme 1). It may be worth to note here that water is a selective solvent for the side PEO chains. The hydrophobic main chains, therefore, are expected to form some organized structures in water. Preliminary experiments suggested the formation of the unimolecular micelle for the graft copolymers in water. ${ }^{25}$ In remarkable contrast, the homopolymer, polymacromonomer, poly $\left(\mathrm{C}_{1}-\mathrm{EO}_{50^{-}}\right.$ $\left.\left(\mathrm{CH}_{2}\right)_{4}-\mathrm{S}\right)$ was found to assume a bottlebrush-like con- formation in water. ${ }^{27}$ The dimensional properties were quantitatively described by a wormlike chain model with a persistence length of $17 \mathrm{~nm}$ and excludedvolume strength of $5.78 \mathrm{~nm}$ in water. ${ }^{27}$

In the present paper, we report many details of the aqueous solution behavior of the graft copolymer, poly(styrene-co- $\left.\mathrm{C}_{1}-\mathrm{EO}_{18}-\left(\mathrm{CH}_{2}\right)_{7}-\mathrm{S}\right)$ and a series of the polymacromonomers, poly $\left(\mathrm{C}_{1}-\mathrm{EO}_{n}-\left(\mathrm{CH}_{2}\right)_{m}-\mathrm{S}\right)$, studied by means of a fluorescence technique using pyrene as a probe, light scattering, and ${ }^{1} \mathrm{H}$ NMR. Direct observation of single macromolecule for the comb-shaped polymers was also challenged by using a scanning force microscopy (SFM). ${ }^{28}$

\section{EXPERIMENTAL}

\section{Materials}

All organic solvents were purified before use according to standard procedure. ${ }^{22}$ In Table I are listed characteristics of the graft copolymer, poly(styrene-co$\left.\mathrm{C}_{1}-\mathrm{EO}_{18}-\left(\mathrm{CH}_{2}\right)_{7}-\mathrm{S}\right)$ and homopolymers, poly $\left(\mathrm{C}_{1}-\mathrm{EO}_{n^{-}}\right.$ $\left.\left(\mathrm{CH}_{2}\right)_{m}-\mathrm{S}\right)$ used in this study. These polymers were prepared by micellar (co-)polymerization of the corresponding macromonomers in water at $60^{\circ} \mathrm{C}$ with $4,4^{\prime}$ azobis(4-cyanovaleric acid), AVA, as an initiator, followed by fractionation to remove the macromonomer unreacted. The details of the preparation were described in the previous papers. ${ }^{22,25}$ The composition in the graft copolymer is [styrene]: $\left[\mathrm{C}_{1}-\mathrm{PEO}-\mathrm{C}_{7}-\mathrm{S}-18\right]=$ $1: 1$. Pyrene (Aldrich) was purified by passing through silica gel column with cyclohexane as mobile phase and by three times recrystallization from ethanol, followed by sublimation. $\mathrm{D}_{2} \mathrm{O}$ (Euriso-top), sodium 2,2dimethyl-2-silapentane-5-sulfonate (DSS) from Merck and $\mathrm{CDCl}_{3}$ (Euriso-top), tetramethylsilane (TMS) from Nacalai Tesque Inc. Kyoto, Japan were used as received. Water purified by a Millpore Milli Q purification system was used in all experiments. 
Solution Properties of Amphiphilic Polymacromonomers

Table I. Characteristics of Poly(styrene-co- $\left.\mathrm{C}_{1}-\mathrm{EO}_{18}-\left(\mathrm{CH}_{2}\right)_{7}-\mathrm{S}\right)$ and Poly $\left(\mathrm{C}_{1}-\mathrm{EO}_{n}-\left(\mathrm{CH}_{2}\right)_{\mathrm{m}}-\mathrm{S}\right)$

\begin{tabular}{|c|c|c|c|c|c|c|}
\hline Polymers & $\frac{10^{-6} M_{\mathrm{w}}^{\mathrm{a}}}{\mathrm{g} \mathrm{mol}^{-1}}$ & $10^{-3} \mathrm{DP}_{\mathrm{w}}$ & $M_{\mathrm{w}} / M_{\mathrm{n}}{ }^{\mathrm{a}}$ & $\frac{R_{\mathrm{h}} \text { in } \mathrm{DMF}^{\mathrm{b}}}{\mathrm{nm}}$ & $\frac{R_{\mathrm{h}} \text { in } \mathrm{H}_{2} \mathrm{O}^{\mathrm{b}}}{\mathrm{nm}}$ & $\begin{array}{c}\text { Weight fraction } \\
\text { of } \mathrm{PEO} / \%\end{array}$ \\
\hline Poly(styrene-co- $\left.\mathrm{C}_{1}-\mathrm{EO}_{18}-\left(\mathrm{CH}_{2}\right)_{7}-\mathrm{S}\right)$ & $7.4_{4}{ }^{\mathrm{c}}$ & $7.8^{\mathrm{c}}$ & $1.8^{\mathrm{c}}$ & 74 & 15 & 73 \\
\hline $\operatorname{Poly}\left(\mathrm{C}_{1}-\mathrm{EO}_{18}-\left(\mathrm{CH}_{2}\right)_{7}-\mathrm{S}\right)$ & $5.5_{5}$ & 5.5 & - & 42 & 45 & 80 \\
\hline $\operatorname{Poly}\left(\mathrm{C}_{1}-\mathrm{EO}_{46}-\left(\mathrm{CH}_{2}\right)_{7}-\mathrm{S}\right)$ & $5.1_{4}$ & 2.3 & 1.4 & 44 & 42 & 91 \\
\hline $\operatorname{Poly}\left(\mathrm{C}_{1}-\mathrm{EO}_{115}-\left(\mathrm{CH}_{2}\right)_{7}-\mathrm{S}\right)$ & 23.4 & 4.4 & 1.7 & - & - & 96 \\
\hline $\operatorname{Poly}\left(\mathrm{C}_{1}-\mathrm{EO}_{469}-\left(\mathrm{CH}_{2}\right)_{7}-\mathrm{S}\right)$ & $2.5_{6}$ & 0.12 & 1.5 & - & - & 99 \\
\hline Poly $\left(\mathrm{C}_{1}-\mathrm{EO}_{46}-\left(\mathrm{CH}_{2}\right)_{1}-\mathrm{S}\right)$ & $4.5_{7}$ & 2.1 & 1.4 & - & - & 88 \\
\hline
\end{tabular}

${ }^{\mathrm{a}}$ Determined by SEC-MALLS in DMF at $40^{\circ} \mathrm{C} .{ }^{\mathrm{b}}$ Determined by DLS. ${ }^{\mathrm{c}}$ Apparent value.

\section{Measurements}

UV measurements were carried out with Shimadzu UV-160A spectrophotometer. Quartz cells with path lengths of $1.0 \mathrm{~cm}$ and $0.1 \mathrm{~cm}$ were used, depending on the concentration of pyrene. Fluorescence excitation and emission spectra of pyrene were recorded with a Shimadzu RF-5300PC spectrophotometer (150W Xenon lamp). Steady state fluorescence spectra were obtained at right angle optical geometry with aerated solutions at $22 \pm 1{ }^{\circ} \mathrm{C}$. The excitation wavelength of $338 \mathrm{~nm}$ was used for pyrene in a hydrophobic environment. Excitation and fluorescence wavelengths were set at 338 and $372 \mathrm{~nm}$ respectively. ${ }^{1} \mathrm{H}$ NMR spectra (JEOL JNM-GX- 270 FT spectrometer) were run on samples in $\mathrm{CDCl}_{3}$ and $\mathrm{D}_{2} \mathrm{O}$ with tetramethylsilane (TMS) and sodium 2,2-dimethyl-2-silapentane-5sulfonate (DSS) as an internal reference, respectively. The condition was 16 times accumulation and $30 \mathrm{~s}$ pulse delay time. Dynamic light scattering (DLS) experiments were performed with an ELS-8000 (Otsuka Electronic Co., Ltd.) equipped with a vertically polarized light of a $10 \mathrm{~mW} \mathrm{He}-\mathrm{Ne}$ laser of $632.8 \mathrm{~nm}$ at $25^{\circ} \mathrm{C}$. Measurements were made at scattered angle of $90^{\circ}$ in temperature-controlled cell maintained via a thermostatically controlled water bath. For an optical purification, the solution was filtered slowly with a membrane filter of $0.45 \mu \mathrm{m}$ in pore size (Toyo Roshi Co., Ltd.) directly into light scattering cells using a microfeeder. The molecular weights of the polymers were determined at $30^{\circ} \mathrm{C}$ with SEC (Shodex Co., Ltd., two Shodex columns, KD-806 M) connected to a refractive index detector and a multi-angle laser light scattering instrument (MALLS) (Wyatt Technology Co., Ltd., DAWN-DSP). The eluent was spectroscopic grade DMF containing $50 \mathrm{mmol} \mathrm{L}^{-1} \mathrm{LiBr}$, and the rate was

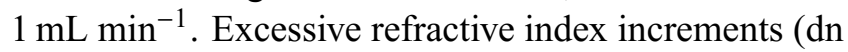
$\mathrm{dc}^{-1}$ ) for the homo- and copolymer were measured using a refractometer, RM-102 (Otsuka Electronic Co., Ltd.). Scanning force microscopy (SFM) was recorded with a Nanoscope III (Digital Instruments, St. Barbara) operated in the tapping mode for the polymer on a mica, at room temperature. ${ }^{28}$ The samples for microscopy measurements were spin cast from water solution, at room temperature.

\section{Pyrene Saturation Experiments}

Pyrene crystals were deposited onto the walls of several centrifuge tubes by gentle evaporation (under a flow of $\mathrm{N}_{2}$ gas) from solutions $(0.5 \mathrm{~mL})$ of pyrene in acetone. Various known concentrations of polymer solutions $(5.0 \mathrm{~mL})$ were added to each tube together with a small magnetic stirring bar. The tubes were closed, and the solutions were stirred at $22 \pm 1{ }^{\circ} \mathrm{C}$ in the dark. The total pyrene concentration solubilized in each solution was determined as follows: First, the excess pyrene microcrystals remaining in the solution were sedimented by centrifugation ( $2000 \mathrm{rpm}, 20 \mathrm{~min}$ ). The supernatant solution was separated with meticulous care and analyzed by UV spectroscopy. Timedependent experiments showed that the pyrene quantity solubilized reaches the saturation level within 3 days. Therefore, the saturation experiment was carried out by stirring each sample for 3 days in the dark.

\section{RESULTS AND DISCUSSION}

\section{Pyrene Partitioning}

The solubilization of an aromatic hydrocarbon such as pyrene into hydrophobic domain allows one to characterize the structure of amphiphilic polymer in water. Figure 1 shows the solubility behavior of pyrene in aqueous solutions of the graft copolymer, poly(styreneco- $\left.\mathrm{C}_{1}-\mathrm{EO}_{18}-\left(\mathrm{CH}_{2}\right)_{7}-\mathrm{S}\right)$ and a series of the homopolymers, poly $\left(\mathrm{C}_{1}-\mathrm{EO}_{n}-\left(\mathrm{CH}_{2}\right)_{7}-\mathrm{S}\right)$ at various polymer concentrations ([Polymer] in $\mathrm{wt} \%)$. There are two interesting aspects to be noted. First is that hydrophobic pyrene molecules are solubilized into the aqueous solutions containing small amount of the polymers. There exists, therefore, in these comb-shaped polymers the favorable hydrophobic space for the dissolution of pyrene molecules. The decrease in the pyrene solubility with increasing PEO chain length is parallel to that the pyrene molecules are solubilized into the vicinity of a hydrophobic backbone in the comb-shaped polymers but not in the PEO chains.

Second is that in all polymer solutions, the concen- 


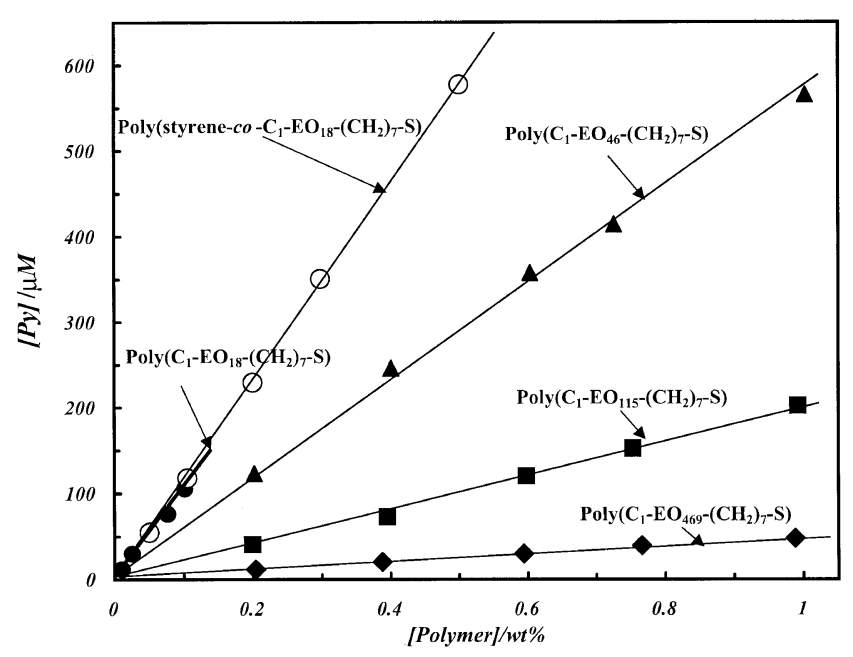

Figure 1. Plots of total quantity of pyrene solubilized in aqueous solutions of polymers as function of polymer concentration [Polymer] ( $\mathrm{wt} \%)$; poly(styrene-co- $\left.\mathrm{C}_{1}-\mathrm{EO}_{18}-\left(\mathrm{CH}_{2}\right)_{7}-\mathrm{S}\right)$ (○), poly $\left(\mathrm{C}_{1}-\mathrm{EO}_{18}-\left(\mathrm{CH}_{2}\right)_{7}-\mathrm{S}\right)(\boldsymbol{\bigcirc})$, poly $\left(\mathrm{C}_{1}-\mathrm{EO}_{46}-\left(\mathrm{CH}_{2}\right)_{7}-\mathrm{S}\right)(\boldsymbol{\Lambda})$, poly $\left(\mathrm{C}_{1}-\mathrm{EO}_{115}-\left(\mathrm{CH}_{2}\right)_{7}-\mathrm{S}\right)(\boldsymbol{\square})$, and poly $\left(\mathrm{C}_{1}-\mathrm{EO} 469-\left(\mathrm{CH}_{2}\right)_{7}-\mathrm{S}\right)(\diamond)$. Measurements were made by UV spectrometry at room temperature.

tration of pyrene almost linearly increases with [Polymer] without any inflection point. This is remarkably contrast to the corresponding macromonomer solutions, in which one clearly observed an inflection point. This point may correspond for critical association concentration $(\mathrm{cac}) .^{29}$ The simple linear relationship between pyrene solubility and [Polymer] in the present polymer solutions suggests that intra- or intermolecular $c a c$ is too low to detect, or there exits no intermolecular association.

To discuss more detail the influence of the chemical structure of the comb-shaped polymer on pyrene solubilization, the data in Figure 1 were re-plotted against monomer unit concentration, ([Cp] in mono$\left.\mathrm{mol} \mathrm{L}^{-1}\right)$, as shown in Figure 2. In the case of the graft copolymer, the mean molecular weight of the monomer unit, styrene and $\mathrm{C}_{1}-\mathrm{EO}_{18}-\left(\mathrm{CH}_{2}\right)_{7}-\mathrm{S}$ is assumed as the monomer molecular weight. It should be noted that the data of $[P y]$ in a series of poly $\left(\mathrm{C}_{1}-\mathrm{EO}_{n}-\left(\mathrm{CH}_{2}\right)_{7}-\mathrm{S}\right)$ solutions are located at a same line within the experimental error. This clearly shows that pyrene dissolution is primarily dominated by the hydrophobic nature of a main chain in the comb-shaped homopolymers.

The slope in the plots of $[P y] v s$. $[C p]$ is related to the partition coefficients $\left(K_{\mathrm{eq}}\right)$ of pyrene. The value of $K_{\mathrm{eq}}$ (mono-mol L $\mathrm{L}^{-1}$ ) is defined by following equilibrium,

$$
[P y]_{\mathrm{w}}^{\mathrm{sat}}+[C p] \stackrel{K_{\mathrm{eq}}}{\rightleftarrows}[P y]_{\mathrm{p}}
$$

where $[P y]_{\mathrm{w}}^{\text {sat }}$ and $[P y]_{\mathrm{p}}$ are the concentration of pyrene in water $\left(7 \times 10^{-7} \mathrm{M}\right)$ and in the polymer phase, respectively. From the simple additivity of the total amount

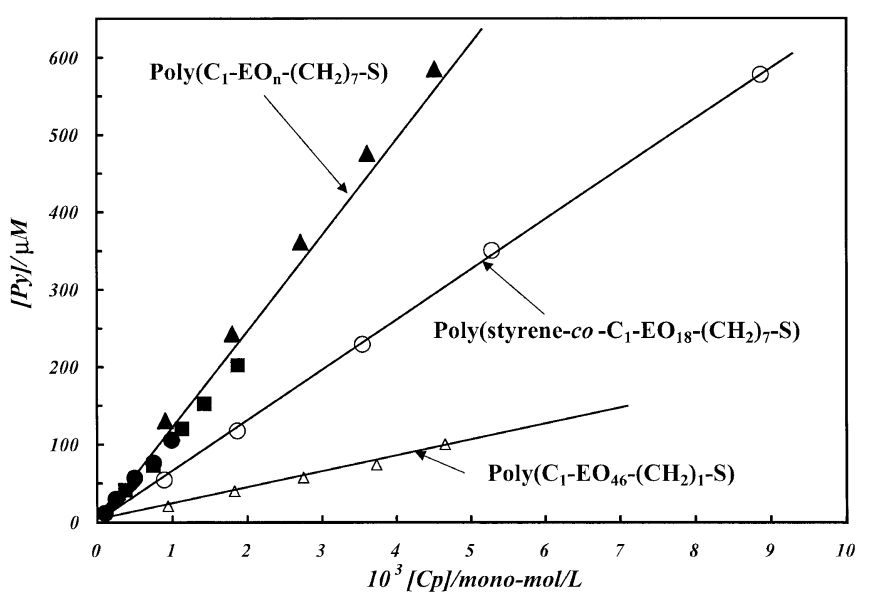

Figure 2. Plots of $[P y]$ as a function of $[C p]$; $\operatorname{Poly}\left(\mathrm{C}_{1}-\mathrm{EO}_{46^{-}}\right.$ $\left.\left(\mathrm{CH}_{2}\right)_{1}-\mathrm{S}\right)(\triangle)$ and other symbols are the same as in Figure 1.

of pyrene dissolved in the polymer solution, that is $[P y]_{\text {total }}=[P y]_{\mathrm{w}}^{\mathrm{sat}}+[P y]_{\mathrm{p}}$, eq 1 can be written as,

$$
[P y]_{\text {total }}=[P y]_{\mathrm{w}}{ }^{\mathrm{sat}}\left(1+K_{\mathrm{eq}}[C p]\right)
$$

The value of $K_{\text {eq }}$ in mono-mol L ${ }^{-1}$ is calculated to be $1.89 \times 10^{5}$ for a series of poly $\left(\mathrm{C}_{1}-\mathrm{EO}_{n}-\left(\mathrm{CH}_{2}\right)_{7}-\mathrm{S}\right)$ solutions. The value is 4.3 times larger than that determined for the corresponding macromonomer, $\mathrm{C}_{1}-\mathrm{EO}_{53^{-}}$ $\left(\mathrm{CH}_{2}\right)_{7}-\mathrm{S}$ micellar solution $\left(K_{\mathrm{eq}}=4.40 \times 10^{4} \mathrm{~mol}\right.$ $\left.\mathrm{L}^{-1}\right) .^{29}$

In the graft copolymer solution, the slope is rather lower than that of poly $\left(\mathrm{C}_{1}-\mathrm{EO}_{n}-\left(\mathrm{CH}_{2}\right)_{7}-\mathrm{S}\right)$ solutions. This is not odd, however, but is due to the fact that the hydrophobic main chain consists of styrene and $p$-heptylstyrene units in the copolymer. To estimate the pyrene solubilizability to the polystyrene moiety, the control experiments were carried out for the solutions of poly $\left(\mathrm{C}_{1}-\mathrm{EO}_{46}-\left(\mathrm{CH}_{2}\right)_{1}-\mathrm{S}\right)$ with $p$-methylstyrene units as a main chain, and the results are also shown in Figure 2. The slope is reasonably very low, implying that $p$-methylstyrene units in poly $\left(\mathrm{C}_{1}-\mathrm{EO}_{46}-\left(\mathrm{CH}_{2}\right)_{1}-\mathrm{S}\right)$ does not provide a favorable space for the pyrene solubilization, when compared to $p$-heptylstyrene units in poly $\left(\mathrm{C}_{1}-\mathrm{EO}_{n}-\left(\mathrm{CH}_{2}\right)_{7}-\mathrm{S}\right)$. Therefore, the slope in the graft copolymer solution reasonably lies intermediate between those in poly $\left(\mathrm{C}_{1}-\mathrm{EO}_{n}-\left(\mathrm{CH}_{2}\right)_{7}-\mathrm{S}\right)$ and poly $\left(\mathrm{C}_{1}-\mathrm{EO}_{46}-\left(\mathrm{CH}_{2}\right)_{1}-\mathrm{S}\right)$ solutions. The values of $K_{\text {eq }}$ in mono-mol L-1 are calculated to be $9.40 \times 10^{4}$ for poly(styrene-co- $\left.\mathrm{C}_{1}-\mathrm{EO}_{18}-\left(\mathrm{CH}_{2}\right)_{7}-\mathrm{S}\right)$ and $2.96 \times 10^{4}$ for poly $\left(\mathrm{C}_{1}-\mathrm{EO}_{46}-\left(\mathrm{CH}_{2}\right)_{1}-\mathrm{S}\right)$ solutions. From Figure 2, one pyrene molecule is calculated to be dissolved in the 8 monomer segments for poly $\left(\mathrm{C}_{1}-\mathrm{EO}_{n}-\left(\mathrm{CH}_{2}\right)_{7}-\right.$ $\mathrm{S}), 15$ for poly(styrene- $\left.\mathrm{co}-\mathrm{C}_{1}-\mathrm{EO}_{18}-\left(\mathrm{CH}_{2}\right)_{7}-\mathrm{S}\right)$, and 51 for poly $\left(\mathrm{C}_{1}-\mathrm{EO}_{46}-\left(\mathrm{CH}_{2}\right)_{1}-\mathrm{S}\right)$. These values may correspond to the distance between the nearest neighboring pyrene molecules to be $2.0,3.8$, and $12.8 \mathrm{~nm}$, respectively, assuming $0.25 \mathrm{~nm}$ as a monomer contour length. 


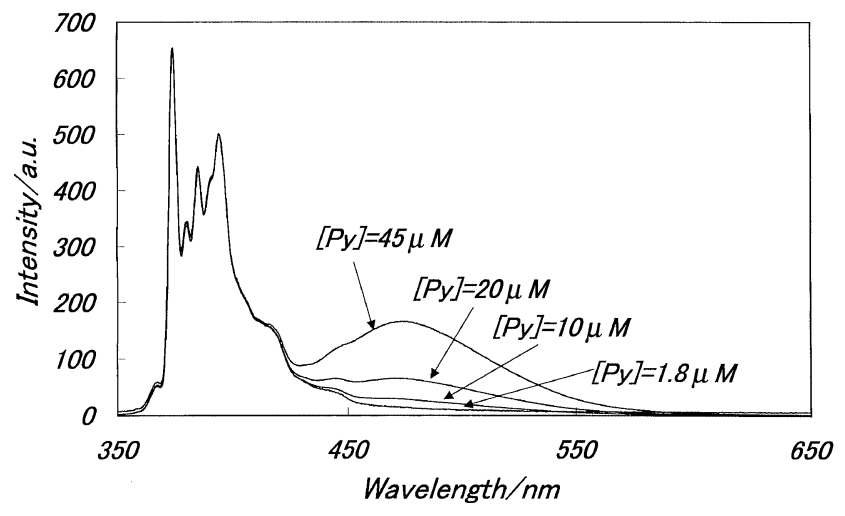

Figure 3. Fluorescence of spectra of pyrene solubilized in an aqueous solution of $0.102 \mathrm{wt} \%$ of poly $\left(\mathrm{C}_{1}-\mathrm{EO}_{46}-\left(\mathrm{CH}_{2}\right)_{7}-\mathrm{S}\right)$. From top to bottom: $[P y]=45,20,10$, and $1.8 \mu \mathrm{M}$ and excitation wavelength $\lambda_{\mathrm{ex}}=338 \mathrm{~nm}$. Each spectrum is normalized at $I_{5}(392 \mathrm{~nm})$.

\section{Vibronic Fine Structure Band Intensity Ratio $\left(I_{1} / I_{3}\right)$}

Among the various fluorescent probes used for characterizing the hydrophobic microdomains, pyrene is most popular and effective because it exhibits a medium-sensitive change in the vibrational fine structure of its emission spectrum. The ratio of the first to third emission band $I_{1} / I_{3}$ changes from 1.8 in water to 0.65 in nonpolar solvents such as hexane. In systems containing both hydrophobic and hydrophilic phases, pyrene is preferentially solubilized into the former. The variation of $I_{1} / I_{3}$ with polymer concentration, therefore, allows one to determine how much hydrophobic microenvironment in our present systems.

Typical fluorescence emission spectra of various pyrene concentrations in poly $\left(\mathrm{C}_{1}-\mathrm{EO}_{46}-\left(\mathrm{CH}_{2}\right)_{7}-\mathrm{S}\right)$ aqueous solution of $1.02 \mathrm{~g} \mathrm{~L}^{-1}$ are shown in Figure 3. The spectra are normalized at the peak of maximum intensity, $I_{5}$, at $392 \mathrm{~nm}$. We note two spectral regions, the monomer emission $c a$. $350-450 \mathrm{~nm}$ and the excimer emission from 450 to $650 \mathrm{~nm}$. We found that the excimer fluorescence intensity $I_{\mathrm{E}}$ is sensitive to $[P y]$ but not the vibronic fine structure intensity ratio $\left(I_{1} / I_{3}\right)$. We obtain $I_{1} / I_{3}=1.48 \pm 0.02$ at this polymer concentration.

In Figure 4, the values of pyrene-saturated solutions are plotted against $[C p]$. In all comb-shaped polymer solutions, the value of $I_{1} / I_{3}$ gradually decreases with increasing $[\mathrm{Cp}]$ without a distinct infection point. The values of $I_{1} / I_{3}$ in poly(styrene-co- $\left.\mathrm{C}_{1}-\mathrm{EO}_{18}-\left(\mathrm{CH}_{2}\right)_{7}-\mathrm{S}\right)$ solutions are almost consistent with those in poly $\left(\mathrm{C}_{1}\right.$ $\left.\mathrm{EO}_{n^{-}}-\left(\mathrm{CH}_{2}\right)_{7}-\mathrm{S}\right)$ solutions, and gradually decrease from 1.5 to 1.2 . The $I_{1} / I_{3}$ in $\operatorname{poly}\left(\mathrm{C}_{1}-\mathrm{EO}_{46}-\left(\mathrm{CH}_{2}\right)_{1}-\mathrm{S}\right)$ solutions is $c a$. 1.65 , which is much higher than that in the former solutions, but close to that in water. In the latter solutions, the pyrene molecules are likely to be located into the interface between the main chain and PEO chain. The agreement of the value of $I_{1} / I_{3}$ in the

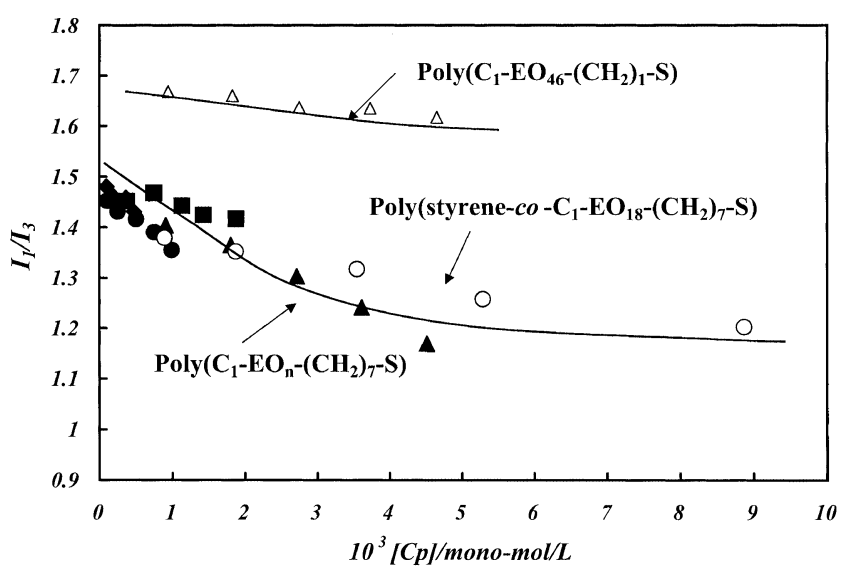

Figure 4. Intensity ratio $\left(I_{1} / I_{3}\right)$ of the vibrational bands of pyrene-saturated solutions against $[C p]$. The symbols are the same as in Figure 2.

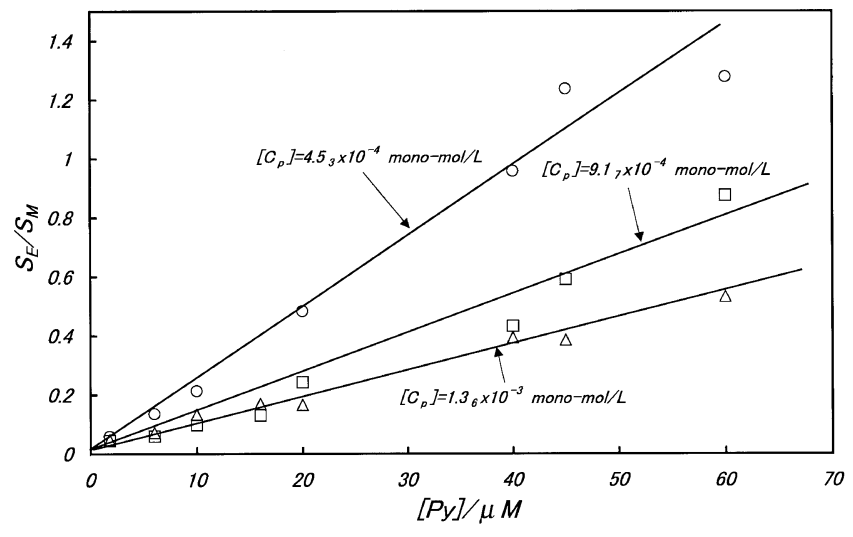

Figure 5. Relative excimer to monomer fluorescence yields $\left(S_{\mathrm{E}} / S_{\mathrm{M}}\right)$ of pyrene in the aqueous solutions of poly $\left(\mathrm{C}_{1}-\mathrm{EO}_{46^{-}}\right.$ $\left.\left(\mathrm{CH}_{2}\right)_{7}-\mathrm{S}\right) ;[\mathrm{Cp}]=4.5_{3} \times 10^{-4} \mathrm{mono}-\mathrm{mol} / \mathrm{L}(\mathrm{O}), 9.17 \times 10^{-4}$ mono$\mathrm{mol} / \mathrm{L}(\square)$, and $1.36 \times 10^{-3} \mathrm{mono}-\mathrm{mol} / \mathrm{L}(\triangle)$.

graft copolymer with that in poly $\left(\mathrm{C}_{1}-\mathrm{EO}_{n}-\left(\mathrm{CH}_{2}\right)_{7}-\mathrm{S}\right)$ implies that the pyrene molecules are preferentially dissolved in the $p$-heptylstyrene units, rather than styrene ones, in agreement with the solubilization results.

\section{Excimer Formation}

As shown in Figure 3, at elevated pyrene concentration in the comb-shaped polymer solutions, excimer emission is observed. Excimer formation is a wellknown phenomenon resulting in the self-quenching of excited monomer fluorescence $I_{\mathrm{M}}$ and the rise of a new excited dimer (excimer) emission $I_{\mathrm{E}}$. In a typical steady-state experiment, one varies $[P y]$ at a fixed $[C p]$, and measures $I_{\mathrm{E}}$ and $I_{\mathrm{M}}$, evaluating $I_{\mathrm{E}} / I_{\mathrm{M}}$. The latter is equal to the relative excimer to monomer luminescence yields $S_{\mathrm{E}} / S_{\mathrm{M}} . S_{\mathrm{E}}$ and $S_{\mathrm{M}}$ were obtained by integrating the fluorescence intensities from 430 to 650 and from 350 to 430 , respectively.

In Figure 5, the values of $S_{\mathrm{E}} / S_{\mathrm{M}}$ in poly $\left(\mathrm{C}_{1}-\mathrm{EO}_{46^{-}}\right.$ $\left.\left(\mathrm{CH}_{2}\right)_{7}-\mathrm{S}\right)$ solution were plotted against $[P y]$. At con- 


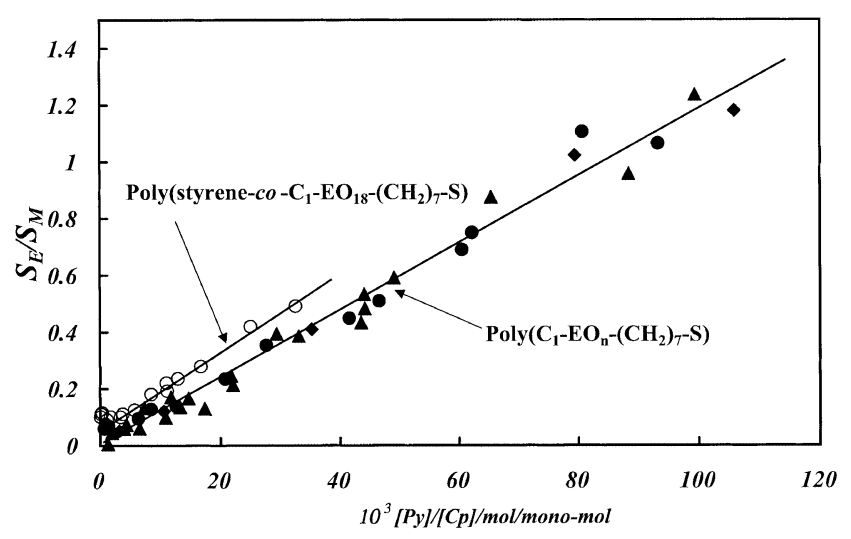

Figure 6. Relative excimer to monomer fluorescence yields $\left(S_{\mathrm{E}} / S_{\mathrm{M}}\right)$ are plotted as a function of local concentration of pyrene, i.e., $[P y] /[C p](\mathrm{mol} / \mathrm{mono}-\mathrm{mol})$. The symbols are the same as in Figure 1.

stant $[C p]$, the $S_{\mathrm{E}} / S_{\mathrm{M}}$ linearly increases with $[P y]$. In addition, at constant $[P y]$ the $S_{\mathrm{E}} / S_{\mathrm{M}}$ decreases with $[C p]$. This is simply a result of the fact that at higher $[P y]$ at constant $[C p]$, the encounter probability of two pyrene molecules increases. In non-micellar homogeneous fluid media, $S_{\mathrm{E}} / S_{\mathrm{M}}$ is known to be linearly dependent on $[P y]$, while in micellar media, a positive curvature is observed. ${ }^{30}$ The simple linear relationship in Figure 5, therefore, may suggest the lacking of the intermolecular association in the polymer solutions.

Figure 6 shows the plots of $S_{\mathrm{E}} / S_{\mathrm{M}}$ with local pyrene concentration, $[P y] /[C p]$. The values of $S_{\mathrm{E}} / S_{\mathrm{M}}$ in poly $\left(\mathrm{C}_{1}-\mathrm{EO}_{n}-\left(\mathrm{CH}_{2}\right)_{7}-\mathrm{S}\right)$ solutions are located on a same straight line within the experimental error. This implies that $S_{\mathrm{E}} / S_{\mathrm{M}}$ is a universal function of the mean number of pyrene molecules per hydrophobic domain. The values of $S_{\mathrm{E}} / S_{\mathrm{M}}$ in the graft copolymer solution are slightly larger than those in poly $\left(\mathrm{C}_{1}-\mathrm{EO}_{n}-\left(\mathrm{CH}_{2}\right)_{7}\right.$ S) solutions.

From the studies on the pyrene fluorescence spectroscopy, one concludes here that the nature of the hydrophobic domain in the graft copolymer, poly(styreneco- $\left.\mathrm{C}_{1}-\mathrm{EO}_{18}-\left(\mathrm{CH}_{2}\right)_{7}-\mathrm{S}\right)$ is not essentially different from that in a series of poly $\left(\mathrm{C}_{1}-\mathrm{EO}_{n}-\left(\mathrm{CH}_{2}\right)_{7}-\mathrm{S}\right)$.

\section{${ }^{1} H$ NMR and Light Scattering}

${ }^{1} \mathrm{H}$ NMR spectra of the copolymers in $\mathrm{CDCl}_{3}$ and in $\mathrm{D}_{2} \mathrm{O}$ are shown in Figures $7 \mathrm{a}$ and $7 \mathrm{~b}$, respectively. In $\mathrm{CDCl}_{3}$ proton peaks ascribed to the phenyl and phenylene were observed at 6.0-7.4 ppm (from TMS). Using TMS as an internal standard in $\mathrm{CDCl}_{3}$, the concentrations of polystyrene residues and PEO chains were calculated. About $98 \%$ of protons due to the polystyrene residues and $100 \%$ due to PEO chains were reasonably detected by ${ }^{1} \mathrm{H}$ NMR, as shown in Figure 7a. In contrast, in $\mathrm{D}_{2} \mathrm{O}$ the peaks due to the polystyrene disap- (a)

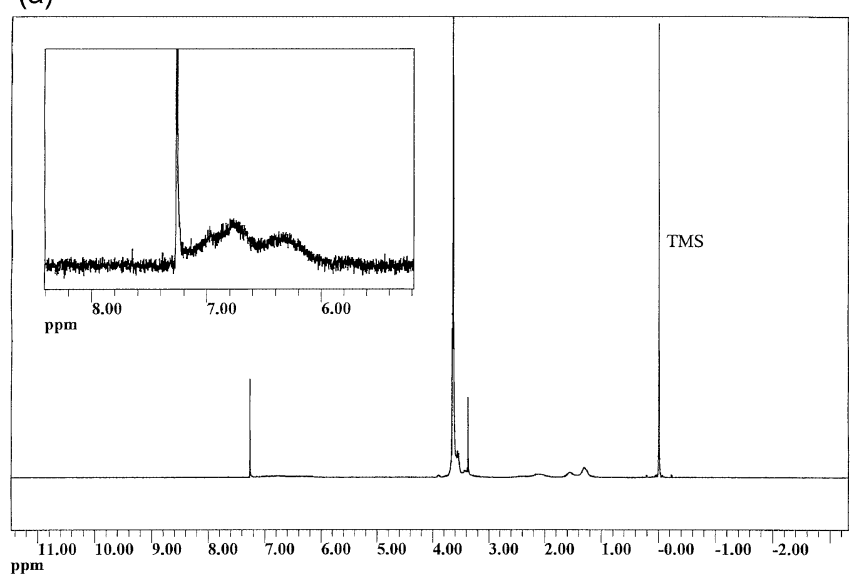

(b)

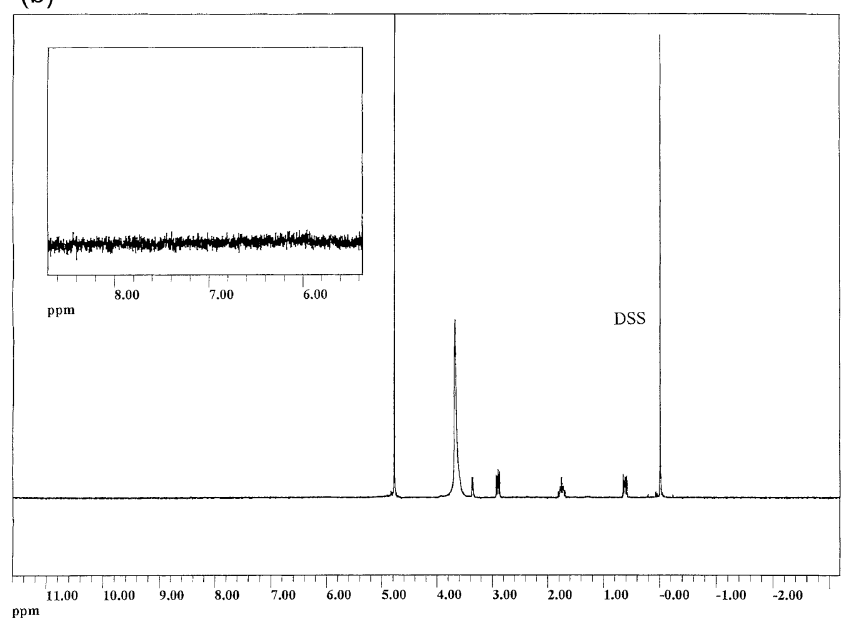

Figure 7. ${ }^{1} \mathrm{H}$ NMR spectrum of poly(styrene-co- $\mathrm{C}_{1}-\mathrm{EO}_{18}-$ $\left.\left(\mathrm{CH}_{2}\right)_{7}-\mathrm{S}\right)$ in $\mathrm{CDCl}_{3}$ (a) and in $\mathrm{D}_{2} \mathrm{O}$ (b). Internal reference in $\mathrm{CDCl}_{3}$ and $\mathrm{D}_{2} \mathrm{O}$ is tetramethylsilane (TMS) and sodium 2,2-dimethyl-2silapentane-5-sulfonate (DSS), respectively.

peared, while PEO chains were quantitatively detected, as shown in Figure $7 \mathrm{~b}$. The restricted motion of the hydrophobic groups due to the formation of association is likely to be responsible in water.

In Table I, the hydrodynamic radius $\left(R_{\mathrm{h}}\right)$ by dynamic light scattering in DMF and in water are listed. For the homopolymers both values are comparable but for the copolymer, the value of $R_{\mathrm{h}}$ in water is much smaller than that in DMF, most likely due to formation of an intramolecular, unimolecular micelle.

\section{Direct Observation of Single Macromolecule by SFM}

The scanning force microscopic picture of $\operatorname{poly}\left(\mathrm{C}_{1}\right.$ $\left.\mathrm{EO}_{46}-\left(\mathrm{CH}_{2}\right)_{7}-\mathrm{S}\right)$ on a mica is shown in Figure 8a. Single, high molecular weight, cylindrical brush-like macromolecule with $c a$. $12.8 \mathrm{~nm}$ in thickness on a mica surface is clearly observed. Pyrene molecules are thought to be dissolved in the center of a noodle, i.e., hydrophobic main chain. The thickness of $12.8 \mathrm{~nm}$ in the cross-sectional direction is comparable to that (11.8 
(a)

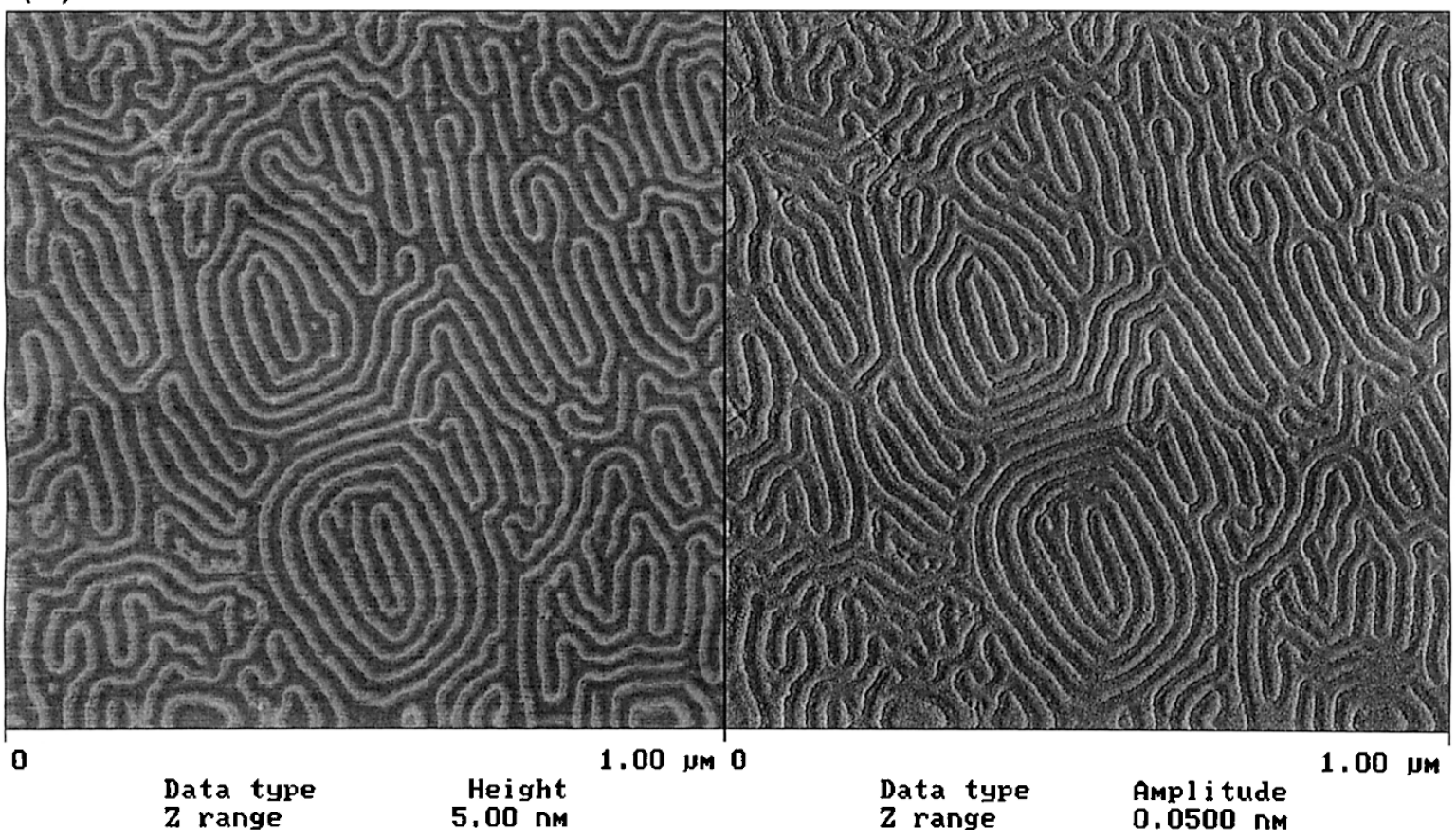

(b)

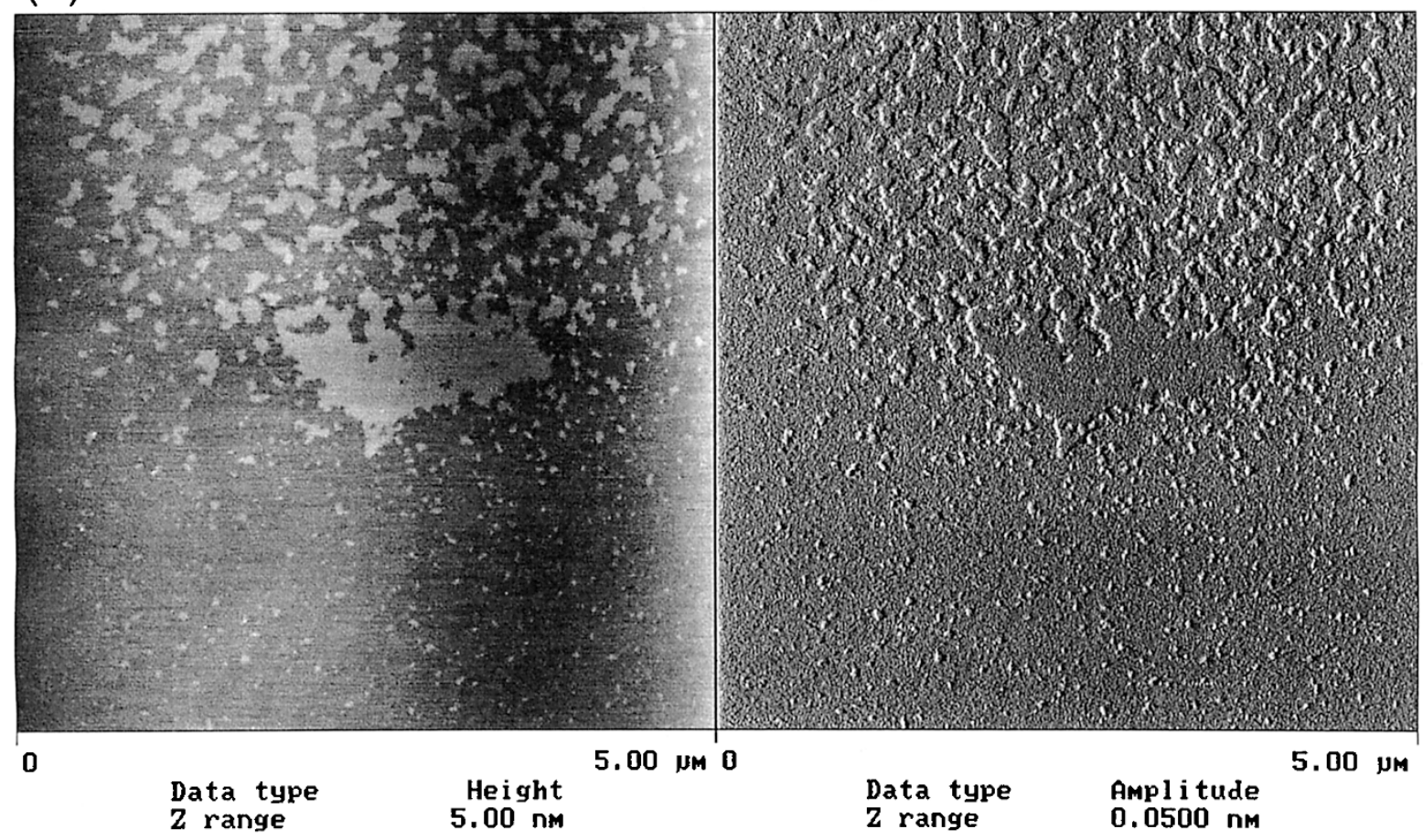

Figure 8. SFM image for (a) poly $\left(\mathrm{C}_{1}-\mathrm{EO}_{46}-\left(\mathrm{CH}_{2}\right)_{7}-\mathrm{S}\right)$ and (b) poly(styrene-co- $\left.\mathrm{C}_{1}-\mathrm{EO}_{18}-\left(\mathrm{CH}_{2}\right)_{7}-\mathrm{S}\right)$ on a mica at room temperature.

$\mathrm{nm}$ ) determined by SAXS measurements in water. ${ }^{31} \mathrm{In}$ remarkable contrast, small fine particles are observed in the SFM picture of the graft copolymers, as shown in Figure 8b. The radius of the particles are likely to be comparable to the value of $R_{\mathrm{h}}$ in water, supporting unimolecular micelle formation in water. Further studies on the dimensional properties of a series of the homopolymers in water and DMF by static light scat- tering, small angle X-Ray scattering, and SFM will be reported soon.

\section{CONCLUSIONS}

In this paper, we describe many details of aqueous solution behavior of poly(styrene-co- $\mathrm{C}_{1}-\mathrm{EO}_{18}-\left(\mathrm{CH}_{2}\right)_{7}$ $\mathrm{S})$ and a series of the homopolymers, $\operatorname{poly}\left(\mathrm{C}_{1}-\mathrm{EO}_{n^{-}}\right.$ 
$\left(\mathrm{CH}_{2}\right)_{m}$-S) studied by means of fluorescence technique using pyrene as a probe, light scattering, ${ }^{1} \mathrm{H}$ NMR, and scanning force microscopy (SFM). Hydrophobic pyrene molecules are exclusively solubilized in the vicinity of hydrophobic $p$-heptylstyrene main chain in these amphiphilic comb-shaped polymers. From the pyrene partitioning, $I_{1} / I_{3}$, and excimer formation, these polymers do not form intermolecular association in water. In addition, the nature of hydrophobic main chain of poly(styrene-co- $\left.\mathrm{C}_{1}-\mathrm{EO}_{18}-\left(\mathrm{CH}_{2}\right)_{7}-\mathrm{S}\right)$ cannot be very distinguishable from that of a series of poly $\left(\mathrm{C}_{1}-\mathrm{EO}_{n}-\left(\mathrm{CH}_{2}\right)_{7}-\mathrm{S}\right)$. However, ${ }^{1} \mathrm{H}$ NMR spectrum of graft copolymer in $\mathrm{D}_{2} \mathrm{O}$ shows highly restricted motion for the main chain. Direct observation of single macromolecule by SFM reveals high molecular weight, cylindrical brush-like macromolecule with $c a .12 \mathrm{~nm}$ in thickness for poly $\left(\mathrm{C}_{1}-\mathrm{EO}_{46}-\left(\mathrm{CH}_{2}\right)_{7}-\mathrm{S}\right)$. In contrast, small particles are observed for the graft copolymers, supporting unimolecular micelle formation in water.

Acknowledgments. This work was supported in part by a Grant-in-Aid (No.09875236), (No. 08455439), and (No. 13650943) from the Ministry of Education, Culture, Sports, Science and Technology. Iriany would like to thank to the Japan International Cooperation Agency (JAICA) for supporting her stay in Japan. M. M. would like to express his grateful acknowledgment to the Ministry of Education, Culture, Sports, Science and Technology for supporting his stay in Japan during his Ph.D. program.

\section{REFERENCES}

1. E. D. Goddard and J. V. Gruber, Ed., "Principles of Polymer Science and Technology in Cosmetics and Personal Care", Marcel Dekker, New York, N.Y., 1999.

2. C. L. McCormick, J. Bock, and D. N. Schulz, "Encyclopedia of Polymer Science and Engineering", John Wiley \& Sons, Inc., New York, N.Y., 1989, vol. 17, p 730.

3. J. Bock, R. Varadaraj, D. N. Schulz, and J. J. Maurer, "Macromolecular Complexes in Chemistry and Biology", P. Dubin, J. Bock, R. M. Davies, D. N. Schulz, and C. Thies, Ed., Springer-Verlag GmbH \& Co., Berlin, 1994, p 33.

4. D. N. Schulz and J. E. Glass, Eds., "Polymers as Rheology Modifiers", Advances in Chemistry Series 462, American
Chemical Society, Washington, D. C., 1991.

5. J. E. Glass, Ed., "Hydrophilic Polymer, Performance with Environmental Acceptability", Advances in Chemistry Series 248, American Chemical Society, Washington, D. C., 1996.

6. J. Selb and Y. Gallot, "Polymeric Amines and Ammonium Salts”, E. J. Goethals, Ed., Pergamon Press, Oxford, 1980.

7. Z. Zhou, B. Chu, and D. G. Peiffer, Macromolecules, 26, 1876 (1993).

8. N. P. Balsara, M. Tirrell, and T. P. Lodge, Macromolecules, 24, 1975 (1995).

9. C. Price and D. Woods, Polymer, 15, 389 (1974).

10. E. Raspand, D. Lairez, and J.-P. Carton, Macromolecules, 27, 2956 (1993).

11. A. Helperin, Macromolecules, 24, 1418 (1991).

12. K. Ito, Prog. Polym. Sci., 23, 581 (1998).

13. K. Ito and S. Kawaguchi, Adv. Polym. Sci., 142, 129 (1999).

14. S. Teramachi, H. Sato, S. Shimura, Y. Watanabe, and Y. Tsukahara, Macromolecules, 28, 6183 (1995).

15. Y. Morishima, S. Nomura, M. Seki, T. Ikeda, and M. Kamachi, Macromolecules, 28, 2874 (1995).

16. K. Akiyoshi, S. Deguchi, N. Noguchi, S. Yamaguchi, and J. Sunamoto, Macromolecules, 26, 3062 (1993).

17. J. Selb and Y. Gallot, Makromol. Chem., 182, 1775 (1981).

18. A. Dondos, P. Remp, and H. Benoit, J. Chim. Phys., 62, 821 (1965).

19. T. Gallot, E. Franta, P. Remp, and H. Benoit, J. Polym. Sci., Part C, 4, 473 (1996).

20. C. Price and D. Wood, Polymer, 14, 82 (1973).

21. A. Kikuchi and T. Nose, Macromolecules, 29, 6770 (1996).

22. K. Ito, K. Tanaka, H. Tanaka, G. Imai, S. Kawaguchi, and S. Itsuno, Macromolecules, 24, 2348 (1991).

23. K. Ito, K. Hashimura, S. Itsuno, and E. Yamada, Macromolecules, 24, 3977 (1991).

24. D. Chao, S. Itsuno, and K. Ito, Polym. J., 23, 1045 (1991).

25. M. Maniruzzaman, S. Kawaguchi, and K. Ito, Macromolecules, 33, 1583 (2000).

26. M. Maniruzzaman, S. Kawaguchi, and K. Ito, Designed Monomers and Polymers, 3, 255 (2000).

27. S. Kawaguchi, K. Akaike, Z.-M. Zhang, H. Matsumoto, and K. Ito, Polym. J., 30, 1004 (1998).

28. S. S. Sheiko, M. Gerle, K. Fisher, M. Schmidt, and M. Möller, Langmuir, 13, 5368 (1997).

29. S. Kawaguchi, Y. Ahmad, J. Duhamel, M. A. Winnik, and K. Ito, J. Phys. Chem., 98, 7891 (1994).

30. A. Yekta, J. Duhamel, P. Brochard, H. Adiwidjaja, and M. A. Winnik, Macromolecules, 26, 1829 (1993).

31. S. Kawaguchi, K. Katsuragi, H. Matsumoto, Iriany, K. Ito, and Y. Muroga, manuscript in preparation. 